\title{
Endurance Capacity and Cardiorespiratory Responses in Sedentary Females During Different Phases of Menstrual Cycle
}

Bandyopadhyay A, Dalui R

Department of Physiology, University of Calcutta University College of Science and Technology

Kolkata, India

\section{Corresponding Author}

Amit Bandyopadhyay

Sports and Exercise Physiology Laboratory

Department of Physiology, University of Calcutta

University College of Science and Technology

Kolkata, India

Email: bamit74@yahoo.co.in

\section{Citation}

Bandyopadhyay A, Dalui R. Endurance Capacity and Cardiorespiratory Responses in Sedentary Females during Different Phases of Menstrual Cycle. Kathmandu Univ Med J 2012;10(4):25-29.

\begin{abstract}
Background

Alteration in physical work capacity of females during different phases of menstrual cycle has been reported in different populations. Pertinent data is unavailable in Eastern Indian population.
\end{abstract}

\section{Objectives}

The present study was aimed to determine the endurance capacity and cardiorespiratory responses during different phases of menstrual cycle in young sedentary females of Eastern region of India.

\section{Methods}

Forty five unmarried young healthy sedentary females (21-25 years) were recruited in the present investigation. Duration of their menstrual cycle was 28-30 days. Cardiorespiratory parameters including the endurance capacity was determined by treadmill running with constant monitoring of heart rate by Polar heart rate monitor.

\section{Results}

The pre-exercise heart rate was significantly higher $(P<0.02)$ in the luteal phase. The peak heart rate was significantly lower $(P<0.02)$ in the flow phase than the follicular and luteal phases. $\mathrm{VO}_{2 \max } \mathrm{O}_{2}$ pulse, maximum pulmonary ventilation and endurance capacity were significantly lower in the follicular phase. However, the endurance capacity was significantly lower in the flow phase. Pre-exercise systolic and diastolic blood pressure did not exhibit any significant variation in different phases of menstrual cycle.

\section{Conclusion}

Therefore, from the present observations it may be concluded that pre-exercise heart rate and respiratory rate are significantly higher in the luteal phase whereas $\mathrm{VO}_{2 \max } \mathrm{O}_{2}$ pulse, maximum pulmonary ventilation, endurance capacity and peak heart rate were significantly lower in the follicular phase.

\section{KEY WORDS}

Endurance capacity, $\mathrm{VO}_{2 \max }$ pulmonary ventilation, menstrual cycle 


\section{INTRODUCTION}

Physical exercise is associated with increase in the rate and depth of ventilation along with an increase in the heart rate, stroke volume and cardiac output to meet the excess metabolic demand of the exercise. Cardiorepsiratory responses to exercise have been studied in female athletes and sedentary women. ${ }^{1-4}$ Ability to perform strenuous physical exercise largely depend on the cardiorespirstory efficiency to take up, transport and give off oxygen for its utilization. ${ }^{5,6}$ Moreover, many literatures depicted that the body composition of an individual deals largely with the physical performance level since the lean body mass plays the role of energy supplier during strenuous physical activity. ${ }^{7-10}$ Moreover, the selection of ergometer is another important aspect to conclude the performance ability of an individual since different ergometers involve different body musculature. $^{11}$

The increasing participation of women in competitive sports has drawn attention of scientists to understand effect of menstrual cycle on athletic performance. ${ }^{12}$ Researches indicated contradictory findings regarding changes in physical work capacity of females during different phases of their menstrual cycle. Pulmonary ventilation increases significantly during the luteal phase whereas cardiorespiratory fitness and peak heart rate were highest in the post-menstrual phase and lowest during the flow phase. ${ }^{13,14}$ However, contradictory findings indicated that cardiorespiratory fitness did not alter in different phases of menstrual cycle. ${ }^{15,16}$ Many studies suggested that different phases of menstrual cycle do not affect the physical performance. ${ }^{17-20}$ While others reported significant impact of different phases of menstrual cycle on the determinants of exercise performance, such as lactate response to exercise, body weight, plasma volume, haemoglobin concentration, heart rate and pulmonary ventilation. ${ }^{21-23}$

The endocrine profile of female hormones is cyclical during their sexual cycles. It is necessary to enquire into the role of such cyclical endocrine profile in maintaining psychic and physical harmony to extract optimum work. A study was conducted in $\mathbf{4 0}$ South Indian females to evaluate their physical work capacity during different phases of menstrual cycle. ${ }^{12}$ Pertinent studies in Eastern Indian females are unavailable with special reference to the impact of body composition on physical work capacity. The present study was therefore conducted to evaluate the endurance capacity and cardiorespiratory responses in sedentary females of Eastern Region of India during different phases of menstrual cycle.

\section{METHODS}

Forty five unmarried healthy sedentary females of 21 to 25 years of age with similar socio-economic background were selected from the post-graduate section of the University of Calcutta, Kolkata, India. All of them were non-smokers and had normal duration of menstrual cycle (28-30 days). They were not under any medication during the study period. Age of each subject was calculated from the date of birth as recorded in the University Register. Body height and body mass were measured with standard instrument with an accuracy of $\pm 0.5 \mathrm{~cm}$ in case of body height and $\pm 0.25 \mathrm{~kg}$ in case of body mass. The basal body temperature was regularly monitored to predict the ovulation that was indicated by a minimum temperature rise of 0.4 to $0.6^{0} \mathrm{~F}^{19}$ Subjects reported in the laboratory at 9 am on the days of evaluation after a light breakfast. They were asked to refrain from any energetic activity on that day. They took complete rest on an easy chair for half an hour so that cardiopulmonary parameters could reach a steady state. ${ }^{20}$ A heart rate monitor was secured on the chest surface of the subject for constant monitoring of heart rate. The preexercise blood pressure was also measured.

The entire experimental protocol was explained to them to allay their apprehension. Ethical permission and written informed consent from each participant were taken for conducting the study.

Experimental protocol was repeated during each phase of one's same menstrual cycle to find out the variation in the studied parameters in different phases of menstrual cycle. The days for experimental trial during different phases of the menstrual cycle were selected according to Doskin VA et al. ${ }^{18}$

- $3^{\text {rd }}$ day of the menstrual cycle (for evaluation in Flow phase)

- $10^{\text {th }}$ day of the menstrual cycle (for evaluation in Follicular phase)

- Between $20^{\text {th }}$ and $24^{\text {th }}$ day of the menstrual cycle (for evaluation in Luteal phase)

Prediction of $\mathrm{VO}_{2} \max ^{24}$

Queen's College step test was performed to predict the $\mathrm{VO}_{2 \max }$.

Determination of Endurance capacity

Work-load selection

After an initial warm-up of five min at a speed of $3 \mathrm{~km}$ $\mathrm{hr}^{-1}$, exercise consisted of treadmill running at a heart rate of 135-140 beats $\mathrm{min}^{-1}$. This heart rate was chosen as an estimate of $70 \%$ of maximal age predicted heart rate or HRmax. The corresponding treadmill speed was $8-10 \mathrm{~km} / \mathrm{h}^{-1}$ without any inclination or slope. Subject was considered exhausted when severe signs of exhaustion were supervened and she could no longer continue the exercise in spite of decreasing the speed of the treadmill.

\section{Determination of Maximum Pulmonary Ventilation}

Low resistance high velocity Collin's triple "J type" plastic valve was used for the collection of gas by open circuit method. $^{23}$ The valve was connected with the Douglas 


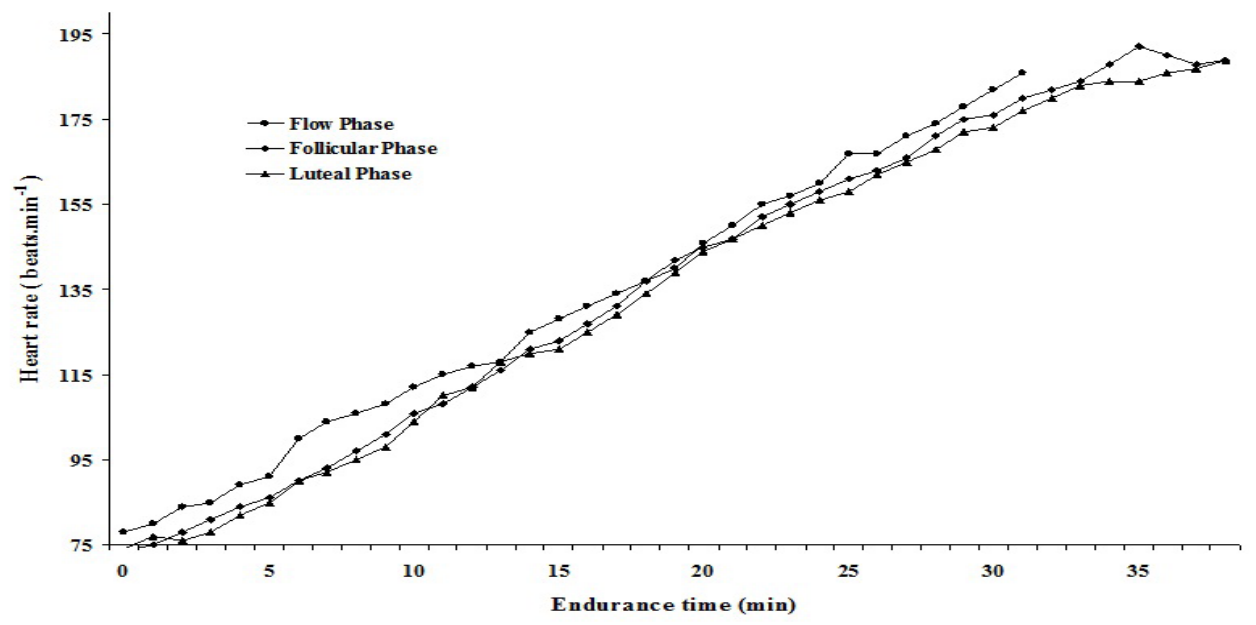

Figure 1. Changes in heart rate during endurance exercise in different phases of menstrual cycle.

Bag $(150$ I) by a standard corrugated rubber tube and the expired gas was collected in the last minute of the endurance exercise. The expired gas was measured in a wet gasometer (Toshniwal, Cat No CG 05.10) to determine the maximum pulmonary ventilation.

All the data have been presented as mean \pm SD. Analysis of variance (ANOVA) was used to compare the difference between means observed in different phases of menstrual cycle.

The entire experiment was conducted at a room temperature varying from $30-34^{\circ} \mathrm{C}$ and the relative humidity ranging between $67-70 \%$.

\section{RESULTS}

The mean of age, body weight and body height of the subjects were $23.4 \pm 2.45$ years, $55.26 \pm 3.28 \mathrm{~kg}$ and 163.01 $\pm 4.34 \mathrm{~cm}$, respectively. Pre-exercise heart rate, respiratory

Table 1.Cardiorespiratory parameters of the subjects in different phases of menstrual cycle.

\begin{tabular}{|c|c|c|c|}
\hline Menstrual phases & Flow Phase & $\begin{array}{l}\text { Follicular } \\
\text { Phase }\end{array}$ & Luteal Phase \\
\hline $\begin{array}{l}\text { Pre-Exercise Heart } \\
\text { Rate (beats.min- }{ }^{-1} \text { ) }\end{array}$ & $75.00 \pm 4.1$ & $72.64 \pm 3.9$ & $78.87 \pm 4.3^{*}$ \\
\hline $\begin{array}{l}\text { Systolic blood pressure } \\
(\mathrm{mm} \text { of } \mathrm{Hg})\end{array}$ & $114 \pm 6.0$ & $112 \pm 6.4$ & $110 \pm 7.0$ \\
\hline $\begin{array}{l}\text { Diastolic blood pres- } \\
\text { sure }(\mathrm{mm} \text { of } \mathrm{Hg} \text { ) }\end{array}$ & $80 \pm 6.0$ & $78 \pm 6.4$ & $76 \pm 7.0$ \\
\hline Respiratory rate & $18.69 \pm 2.19$ & $18.06 \pm 2.57$ & $20.51 \pm 2.40 * *$ \\
\hline $\begin{array}{l}\text { VO2max (mL.kg- }{ }^{1} . \\
\left.\min ^{-1}\right)\end{array}$ & $36.87 \pm 2.9 * *$ & $39.95 \pm 2.4$ & $39.64 \pm 2.4$ \\
\hline $\begin{array}{l}\text { Maximum Pulmonary } \\
\text { Ventilation }\left(\text { L. } \min ^{-1}\right)\end{array}$ & $50.75 \pm 5.4 *$ & $58.05 \pm 5.3$ & $58.31 \pm 4.4$ \\
\hline $\mathrm{O}_{2}$ Pulse (mL.beat ${ }^{1}$ ) & $8.89 \pm 0.9 * *$ & $9.60 \pm 0.80$ & $9.41 \pm 0.8$ \\
\hline $\begin{array}{l}\text { Endurance capacity } \\
\text { (min) }\end{array}$ & $31.3 \pm 1.0 * *$ & $38.0 \pm 1.0$ & $37.8 \pm 0.9$ \\
\hline $\begin{array}{l}\text { Peak Heart Rate } \\
\text { (beats. } \mathrm{min}^{-1} \text { ) }\end{array}$ & $185.80 \pm 2.8 *$ & $188.87 \pm 3.6$ & $188.73 \pm 3.1$ \\
\hline
\end{tabular}

Values are mean $\pm \mathrm{SD} ;{ }^{*} \mathrm{P}<0.02, * * \mathrm{P}<0.001$ rate, systolic and diastolic blood pressure, $\mathrm{VO}_{2 \max } \mathrm{O}_{2}$ pulse, maximum pulmonary ventilation, endurance capacity and peak heart rate of the subjects are presented in table 1 . The pre-exercise heart rate was significantly higher $(P<0.02)$ in the luteal phase. The peak heart rate was significantly lower $(P<0.02)$ in the flow phase than the follicular and luteal phases. $\mathrm{VO}_{2 \text { max }}, \mathrm{O}_{2}$ pulse, maximum pulmonary ventilation and endurance capacity were significantly lower in the follicular phase. Working heart rates recorded in each min during endurance exercise in different phases of menstrual cycle were represented in fig 1.

\section{DISCUSSION}

There is a conceptual fact that the cardiac output is proportionate to the $\mathrm{VO}_{2 m a x}{ }^{25,26}$ The maximum stroke volume is achieved at an oxygen consumption of $40 \%$ of $\mathrm{VO}_{2 \max }$ and mean pulse rate of $110 / \mathrm{min} .{ }^{27}$ Therefore the further increase in cardiac output with increase in workloads is solely attributed to the increase in heart rate that is limited to $170-180$ beats. $\mathrm{min}^{-1}$ beyond which the diastolic period decreases leading to less filling of the heart. ${ }^{27}$ So pulse rate is an estimate of the limit to which cardiac output can be increased. ${ }^{12}$

$\mathrm{VO}_{2 \max }$ has been globally accepted as the determinant of maximal performance capacity and it is primarily controlled by cardiovascular transport rather than pulmonary capacity since cardiovascular adjustment plays the chief role in oxygen transport. ${ }^{28}$ Linear relationship among pulse rate, cardiac output and maximum oxygen consumption is also established. ${ }^{26,27}$

On the basis of these principles Wahlund proposed the concept of $\mathrm{PWC}_{170}$ which was later modified by Watson and Donovan. ${ }^{23,25,29}$ But, procedure for determination of $\mathrm{PWC}_{170}$ involves bicycle exercise that does not involve the whole body musculature. Considering this fact, to involve the activity of entire body musculature, in the present study the exercise in treadmill has been preferred.

Endurance capacity, $\mathrm{O}_{2}$ pulse, peak heart rate, $\mathrm{VO}_{2 \max }$ and 
maximum voluntary ventilation were significantly lower in the luteal phase although these parameters did not show any significant difference between the exercise trials in follicular and flow phases (table 1). Similar findings are evident in case of working heart rates during the different phases of menstrual cycle (Fig 1). Pre-exercise heart rate was significantly higher $(P<0.02)$ in the flow phase. Such increase in resting heart rate during luteal phase was probably because of increased sympathetic activity resulted from inflated cardiovascular response to hormonal changes. ${ }^{18}$ The preliminary links in the $\mathrm{O}_{2}$ transport chain are cardiovascular and respiratory system. Increased pre-exercise respiratory rate during luteal phase might be attributed to increased progesterone induced enhancement in sensitivity of respiratory centers to $\mathrm{CO}_{2}$ during endurance exercise. ${ }^{12,30}$ The decreased mechanical efficiency of the respiratory system due to this leads to increased $\mathrm{O}_{2}$ consumption by respiratory muscles themselves, leading to a point nearer to critical ventilation. ${ }^{31}$ This might be the cause of higher value of pulmonary ventilation during the luteal phase.

Elevated sympathetic activity during luteal phase intensifies the increment in HR during exercise that in turn reduces the cardiac output. ${ }^{17}$ Existence of higher heart rate and respiratory rate during luteal phase may be due to the fact that aerobic capacity or work done is directly proportional to the cardiac output that is met with the exaggerated HR and $R R$ responses to exercise stimulus through sympathetic activity. ${ }^{17}$ Thus the cardiovascular system and respiratory system are the links in limiting $\mathrm{O}_{2}$ transport during luteal phase and that might be the cause of existence of highest value of $\mathrm{VO}_{2 \max }$ in the luteal phase.

\section{REFERENCES}

1. Åstrand I. Aerobic capacity in men and women with reference to age. Acta Physical Scand 1960; $49: 1-5$.

2. Saltin B, Åstrand PO. Maximal oxygen uptake in athletes. J Appl Physiol 1967; 23: 353-7.

3. Kilbom A. Submaximal intensities in women. Scand J Clin Invest 1971; $28: 141-7$.

4. Drinkwater $\mathrm{BL}$, Horvath $\mathrm{SH}$, Wells $\mathrm{CL}$. Aerobic power of females aged 10-68 years. J Garont 1975; $30: 385-92$.

5. Taylor HL, Buskirk E, Henschel A. Maximum oxygen uptake as an objective measure of cardiorespiratory performance. J Appl Physiol $1955 ; 8 ; 73-8$.

6. Hettinger T, Birkhead NC, Horvath JM, Issekntz B, RodahI K. Assessment of physical work capacity. J Appl Physiol 1961; $36: 711$ - 15.

7. Gitin EL, Olerud JE, Carroll HW. Maximal oxygen uptake based on lean body mass, a meaningful measure of physical fitness. J Appl Physiol 1974; 36: $757-62$.

8. Kitagawa K, Ikuta K, Hirota K, Hara Y. Investigation of lean body mass as a limiting factor of maximum oxygen uptake. J Phys Fit 1974; 23: $96-105$.

9. Kitagawa K, Miyashita M, Yamamoto. Maximal oxygen uptake, body composition and running performance in young Japanese adults of both sexes. Jap J Phys Edu 1977; 21 : 335 - 41.
The endurance capacity was significantly lower in the flow phase as also reported in terms of $\mathrm{PWC}_{170}$ in Japanese, Western and Indian population from other provinces. ${ }^{17,18,32,33}$ However the findings were contradictory to the findings of Doolittle et.al. ${ }^{34,35}$

Various psychophysiological factors are also responsible for altered exercise performance during different phases of menstrual cycle. Neurological constituents which acquire somatic manifestations are the psychic factors whereas fluid retention in the muscles is physiological factors which cause pain, discomfort and decreased muscular contraction. ${ }^{33,36}$ According to Girija B et al Indian social perspectives are also to some extent act as a stigma to menstruating women and this may also be considered as a factor to decrease the performance. ${ }^{12}$ They also hypothesized that estimation of female sex hormones during different phases and its correlation to working capacity may reveal more facts.

The present observations corroborated with the earlier studies in Indians, Japanese and Western populations. ${ }^{17,32,33,36}$ However, the pre-exercise systolic and diastolic blood pressure did not exhibit any significant variation in different phases of menstrual cycle.

\section{CONCLUSION}

Therefore, from the present observations it may be concluded that pre-exercise heart rate and respiratory rate are significantly higher in the luteal phase although systolic blood pressure, diastolic blood pressure and working heart rates did not change during different phases of menstrual cycle. On the other hand, $\mathrm{VO}_{2 \max }, \mathrm{O}_{2}$ pulse, maximum pulmonary ventilation, endurance capacity and peak heart rate were significantly lower in the follicular phase.

10. Watanabe K, Nakadomo F, Maeda K. Relationship between body composition and cardio-respiratory fitness in Japanese junior high school boys and girls. Ann Physiol Anthropol 1994; 13 : 167 - 75.

11. Chatterjee $S$, Chakravarti B. Comparative study of maximum aerobic capacity by three ergometers in untrained college women. Japn J Physiol 1986; 36 : 151-62.

12. Girija B, Veeraiah S. Effect of different phases of menstrual cycle on physical working capacity in Indian population. Indian J Physiol Pharmacol 2011; $55: 165-9$.

13. Mline JA. The respiratory response to pregnancy. Postgrad Med J $1975 ; 55: 318-21$.

14. Chatterjee $P, N a g ~ S$, Kali $M$, Chatterjee $S$. Study on $\mathrm{VO}_{2 \max }$ of female athletes in relation to menstrual cycle. Ind J Physiol \& Allied Sci 1988; $42: 11-21$.

15. Gamberale F. Effects of menstruation on work performance. Ergonomics 1985; 28: 19-25.

16. Sarkar S, Nag S, Chatterjee P. Menstrual cycle - its effects on some cardiorespiratory responses to exercise. Biomed 1996; 16 : 33-39.

17. Mehta V, Chakrabharthy AS. Autonomic functions during different phases of menstrual cycle. Indian J Physiol Pharmacol 1993; 37: 56 -62 . 
18. Doskin VA,Kozeeva TV, Listskaya TS, Shokina E. Changes in working capacity of female athletes in different phases of menstrual cycle. Human Physiol 1979; 5: 144-9.

19. Gamberale F, Strindberg L, Wahlberg I. Female work capacity during the menstrual cycle, Physiological and psychological reaction. Indian J Physiol Pharmacol 2011; 55: 2-8.

20. Silla RV, Khaas L. Changes in the mental and physical work capacity of girls during the menstrual cycle. Gig Snit 1975; 11: 32-8.

21. Brian and Davies, Jullan ND, Efford CC. Variations in performance in simple muscle tests at different phases of menstrual cycle. J Sports Med Phys Fitness 1991; 31: 532-9.

22. Redman Lm, Scroop GC, Norman RJ. Impact of menstrual cycle phase on the exercise status of young, sedentary women. Eur J App Physiol 2003; $90: 505-10$.

23. Xanne AK, de Jonge J. Effects of the Menstrual Cycle on Exercise Performance. Sport Med 2003; 33: 833-7.

24. Chatterjee P. Study on $\mathrm{VO}_{2 \max }$ of female athletes in relation to menstrual cycle. Med Sci Sport Exerc 1995; 27: 437-45.

25. Wahland H. Determination of physical working capacity. Acta Med Scand 1948; 1: 1-6.

26. Wade OL, Bishop JM. Relationship between oxygen consumption and cardiac output in cardiac output and regional blood flow in Physiology. London:Oxford-Blackwell Publication;1962.pg 1-6.
27. Strand PO, Rhyming I, Cuddy Te. Cardiac output during submaximal and maximal work. J Appl Physiol 1954; 7: 218-22.

28. Hill AV,Long CNH. Cardiac Transport and not Pulm Transport is the limiting factor in oxygen transport in Physiological basis of medical practice. William and Wilkins Publications:Baltimore;1966 pg. 359.

29. Watson AWS, Donovan DJ. Influence of level of habitual activity on physical working capacity and body consumption of post pubertal school boys. J Expl Physiol 1977; 60: 325-31.

30. Dutton P, Blanksby BA, Morton AR. CO2 Sensitivity changes during the menstrual cycle. J Appl Physiol 1989; 42: 42-7.

31. Bempsey J, Hanson P, Pegelow D, Fregon R. Mechanical Vs Chemical determinants of hyperventilation in heavy exercise. Med Sci Sports Exerc 1982; 14: 131-

32. Mesaki NS. Effect of menstrual cycle on cardio-respiratory system during incremental exercise. Japannese Obst \& Gynaec 1986; 38:1-9.

33. Lebrum CM. Effect of menstrual cycle phase on athletic performance. Med Sci Sports Exerc 1995;27:437-44.

34. Doolittle P, Engegresten R. Performance variations during menstrual cycle. J Sports Med Phys Fit 1972;12:54-9.

35. Brian D, Julian ND, Efford CC. Variation in performance in simple muscle test at different phases of menstrual cycle. J Sports Med Phys Fit 1991;31:532-7.

36. Peter VK. Physiology of muscular activity. W.B. Saunders company, 7 (1959) 266. 